\title{
LA FORMACION DEL ESPIRITU CIENTIFICO EN COLOMBIA
}

Gabriel Restrepo*

Sumario: Este ensayo fue extraído de una investigación que el autor realizó para Colciencias entre 1980 y 1982 sobre la evolución de las actividades científicas en Colombia. En él se examina la formación del espíritu científico que tuvo lugar en la Nueva Granada en el período de la ilustración. Se destacan las condiciones que hicieron propicia en la Metrópoli y en las Colonias la difusión del "ethos científico" que se había incubado en la esquina noroccidental de Europa. Se destacan las grandes expediciones científicas. Se subraya el papel de la Expedición Botánica y en particular de su director, José Celestino Mutis, en la formación del espíritu científico en Colombia. Por último, se consideran las repercusiones de la llustración en el sistema educativo.

\section{El viraje de la ilustración}

El siglo XVIII fue el punto de viraje en la condición del Nuevo Reino, determinado por una confluencia de modificaciones sustanciales en la metrópoli y en las colonias.

En España, el cambio de dinastía (de los Austrias a los Borbones) favoreció el acercamiento de España a la dinámica europea. Surgió entonces un liderazgo modernizador ilustrado. Un aumento demográfico, con mucha vitalidad de las regiones periféricas (Cataluña, Asturias, países Vascos) dio nuevo aliento a la sociedad española.

Cambios en gran escala ocurrían simultáneamente en las colonias. La penetración de potencias europeas en América Hispana continuaba su curso inexorable (Guyana, Belice, el Caribe), y era cada vez más importante como punto de apoyo al contrabando económico, pero también al "contrabando intelectual". Un mayor asentamiento de la población en territorios ya totalmente descubiertos y un mestizaje cada vez más activo fueron fenómenos distintivos del período.

Había cesado el ímpetu evangelizador. En consecuencia, disminuía el papel de las órdenes religiosas. Las colonias tendían ya hacia un espíritu más secular. Como lo reconocían Jorge Juan y Antonio Ulloa, podía hablarse ya de una casta de criollos, con identidad cultural propia y con recursos derivados de la combinación de actividades mineras, agrícolas y sobre todo comerciales.

Así, una vida urbana, premisa como se sabe de todo florecimiento de la cultura, comenzó a ser incipiente en las postrimerías del siglo XVIII: en lugar de las audiencias cautivas de las iglesias o de las prédicas, en lugar de los rumores y de los ritos religiosos, surgieron un público, periódicos, actividades teatrales y asociaciones voluntarias para el cultivo de las letras, de las ciencias y de los negocios.

España y sus colonias se fueron abriendo paulatinamente a la influencia europea, si bien el cambio era inducido apenas desde arriba, con vacilaciones, por una pequeña élite que luchaba contra la fuerza de una tradición arraigada y contra intereses que resistían el empeño de los novatores. Feijoo, un benedictino, fue el adelantado en las humanidades, encargado de divulgar desde un ángulo deísta (valor fundamental en la difusión española) los valores de la ciencia moderna, mientras que Campillo y Ensenada iniciaban en la

\footnotetext{
${ }^{*}$ Sociólogo. Universidad Nacional. Director de la Unidad de Desarrollo Social. Departamento Nacional de Planeación.
} 
primera mitad del siglo las reformas en la hacienda y en la organización del Estado español.

\section{La gran expedición científica}

Primera proyección en las colonias de una actividad científica organizada, a gran escala, y de una apertura no mediada hacia los centros científicos de la región noroccidental de Europa fue la Expedición ordenada por la Academia de Ciencias de París para medir un grado del meridiano en el Ecuador. Fue encabezada por La Condamine y se llevó a cabo entre 1735 y 1745. A esta memorable Expedición asistieron en calidad de adjuntos los ingenieros y oficiales españoles, Jorge Juan y Antonio de Ulloa, incluidos por expresa condición de la Corona española, que podía aceptar o negar esta intrusión científica.

La Expedición tenía objetivos científicos y políticos. Como las otras dos expediciones que simultáneamente se realizaban en Laponia y en Francia, se proponía ser experimento conclusivo para determinar la forma de la Tierra: achatada hacia los polos, según la anticipada predicción teórica de Newton, más estrecha en el Ecuador, según el cosmógrafo Cassini de París. Algo más que la rivalidad nacional por la emulación científica estaba entonces en juego: las observaciones sobre la figura correcta de la Tierra serían de enorme valor para la navegación, clave del poder económico, político y militar en la época.

Era la primera vez que el interior de América Hispana se ofrecía al examen directo del nuevo espíritu científico europeo. La expedición fue fecunda en resultados adicionales: demostró a la Corona, y en particular a Campillo y a Ensenada, sus ministros de hacienda, que no podría España sostener sus dominios sin el apoyo científico. Jorge Juan y Antonio de Ulloa iniciaron, por su cuenta, una indagación muy juiciosa sobre la estructura militar, política y social de las colonias. Por supuesto, resultó ser muy crítica y por tanto serviría como fundamento para reorientar la política de la metrópoli.

Aparte de los valiosos materiales publicados por La Condamine, y de los hallazgos y nuevas noticias sobre viejos y nuevos productos americanos, Jorge Juan y Antonio de Ulloa publicaron y escribieron diversos informes de incalculable valor etnográfico, histórico y sociológico, que quizás inmerecidamente fueron opacados por los escritos posteriores de Humboldt. Entre ellos sobresalieron: Relación histórica del viaje por América Meridional, y las famosas Noticias Secretas, divulgadas éstas en 1826 por los ingleses como arma de propaganda contra el dominio colonial español.

Como hecho singular, cabe destacar que la Expedición incorporó por primera vez a un criollo, el ecuatoriano Maldonado, en actividades científicas de relevancia mundial. Merece subrayarse, también, que la Expedición revelaba cuánta hostilidad e incomprensión existían en las colonias en relación con la investigación natural y social: los campesinos no podían comprender qué hacían aquellos hombres encaramados en las cumbres, con aparatos que a su ver eran endemoniados: achacaban aquello a brujería o lo tomaban como búsqueda de guacas o tesoros ocultos.

Aunque las observaciones de Jorge Juan y de Antonio de Ulloa sirvieron al parecer para rediseñar la política de la Corona hacia sus colonias, no puede hablarse aún de una transferencia de conocimientos en beneficio de la América Hispana, salvo el muy singular y excéntrico caso de Maldonado.

\section{El impulso renovador}


En el contexto del ascendiente de la teoría fisiocrática (mediados del siglo XVIII), España comenzó a comprender que la riqueza de una nación no fincaba en la extracción minera, pero sí en la aplicación metódica al desarrollo de la agricultura: sobre tal edificio se había de estimular el comercio y la manufactura de bienes. Por supuesto, la minería no sería en este esquema tarea desdeñable, pero también allí debería sustituirse el empirismo por el uso de conocimientos teóricos (estratigrafía, química, metalurgia, geología comenzaban a esbozarse como ciencias modernas) y en artes sofisticadas (ingeniería).

España carecía de bases institucionales y de recursos humanos para explotar esas riquezas con fundamentos científicos, pero en la segunda mitad del siglo realizó un notable esfuerzo por crearlos: enviando a jóvenes en calidad de aprendices a los semilleros de cultura científica y técnica en París, Montpellier, Austria, Sajonia o Suecia, o invitando a científicos y técnicos extranjeros a España.

Así, se establecieron en España algunas bases institucionales, como el Jardín Botánico de Madrid, el Seminario de Vergara, o el Instituto Asturiano. Papel directriz en el proceso jugaron las Sociedades Económicas de Amigos del País que se crearon con entusiasmo y aceleración en las distintas regiones de la metrópoli. Pero a diferencia de las Academias Científicas del resto de Europa (España careció estrictamente de ellas, salvo en las humanidades), las sociedades eran más difusas en sus fines (no se propusieron el avance del saber por el saber), más utilitarias y menos selectivas en la inclusión de sus miembros.

De otra parte, España privilegió el intercambio con centros de cultura científicos y técnicos de países que carecieron de una proyección atlántica, tales como Alemania, Austria o Suecia, por razones de la competencia política y económica.

En las colonias se manifestó el impulso renovador en la economía y en la organización de los asuntos públicos, con una notable excepción muy bien advertida por los criollos: no se fomentaba en profundidad la producción de manufacturas que pudieran competir con las españolas, hecho que no obstaculizaba la expansión de un tráfico interno de telas bastas y de frutos de la tierra, como se llamaba en la época a lo producido para los mercados internos. Pero en general, se asignaban ya "funciones naturales" a las regiones en la división internacional del trabajo, según las cuales las colonias habrían de especializarse en el suministro de materias primas agrícolas y mineras.

Para lo anterior era preciso apoyarse en ciencias y técnicas modernas que descubrieran y describieran estas riquezas potenciales: botánica, mineralogía, geografía y agronomía. Y ello no era posible sin alterar radicalmente la atmósfera barroca que carecía de ojos y de sentidos para la contemplación de la naturaleza. La crítica a los prejuicios, a las supersticiones era un hecho revolucionario. La modificación de la concepción natural significaba al mismo tiempo un enjuiciamiento a las creencias sociales y a la imagen santificada y quietista de la sociedad. Así, el despotismo ilustrado, que demandaba un cambio económico, socavaba las bases tradicionales de legitimación del orden colonial.

\section{Nuevas expediciones científicas}

A partir de la Expedición de La Condamine se multiplicaron las exploraciones del interior del continente americano. Leofling, discípulo aventajado de Linneo, fue incorporado a la expedición de límites con los dominios portugueses en América del Sur, pero murió prematuramente en Venezuela, en 1755. 
Las dos décadas precedentes a la revolución francesa, bajo Carlos LII, fueron época cimera en los dominios españoles: en materia científico-técnica se organizaron tres expediciones mineras con el fin de difundir y aplicar las técnicas de amalgamación descubiertas o redescubiertas por el barón de Born en 1785: se dirigieron a Nueva España, Perú y Nueva Granada. A las mismas regiones se habían encauzado tres expediciones botánicas. $Y$ en fin, España se había propuesto emular las recientes empresas exitosas de Cook y Bougainville, mediante la circunnavegación dirigida por el italiano Malaspina, a la que se incorporó también el naturalista austriaco Tadeus Hanke, entre otros científicos destacados. Hanke se radicaría en Cochabamba, y exploraría los recursos naturales de la región austral (guano, salitre, etc.).

En el curso de las expediciones mineras, España y sus colonias se pondrían en contacto con los centros más avanzados en química y metalurgia (Francia, Sajonia y Austria) y llegarían a contribuir al desarrollo mundial de la química con el hallazgo (más que descubrimiento) de la platina y del wolfranio. A la vez, las expediciones mineras fomentarian en las colonias la constitución de centros de investigación y docencia en minería, siendo el colegio de Minería de México el más exitoso. En la Nueva Granada, consta que Mutis propuso un colegio similar al de México, pero no se fundaría hasta 1823, y aún entonces no prosperaría: sólo hasta la inauguración de la Escuela de Minas, a finales del siglo XIX, se haría realidad una idea ya anunciada bajo la idea de la ilustración. En Botánica, España se incorporó al paradigma de Linneo, y éste se difundió a las colonias por medio de las Expediciones Botánicas.

El impulso renovador fue sin embargo precario: la reacción antifrancesa y las guerras de independencia, hechos a los que se sumaron las deficiencias estructurales de la sociedad española y de sus colonias, arruinaron la tendencia y dieron al traste con la continuidad orgánica del impulso científico. Una de las peores consecuencias fue la dispersión de materiales de la generación que bajo la iniciativa de Carlos III había explorado el continente americano. De esta forma, el redescubrimiento de América pasaría por ser obra de un alemán: Alejandro de Humboldt.

\section{Lo distintivo del Nuevo Reino}

Características específicas poseía el Nuevo Reino que lo diferenciaban de los Virreinatos de Nueva España y del Perú. Pobre en plata, aunque importante productor de oro, el Nuevo Reino careció del fausto, de la nobleza y las descomunales distancias sociales que caracterizaron a los reinos erigidos sobre Potosí o Zacatecas. Sólo en el siglo XVIII se constituyó como Virreinato, y sus debilidades económicas y políticas se tradujeron en la medianía de sus instituciones culturales. La imprenta se introdujo con notable retraso. Careció de Universidad Regia, y su cultura estuvo más determinada por las órdenes religiosas que regentaban universidades caseras o conventuales.

Otros factores empero pudieron ser acaso más favorables, como ha anotado agudamente Jaime Jaramillo Uribe. Siendo la población indígena mucho menor, se produjo más aceleradamente un proceso de mestizaje. Fue así mucho más posible integrar a la población en religión, lengua x' costumbres. A diferencia de Nueva España o Perú, el Nuevo Reino carecía de un centro o capital de la importancia de Lima o México. Había una movilidad de la élite criolla, vinculada al comercio y a la minería, que reducía las grandes barreras regionales. La diferenciación geográfica y regional fue fenómeno tan típico, como el menor abismo entre élite y masa: existía pues un sector medio de criollos dispersos en las provincias que podía ser dirigido a las ideas de la ilustración desde un centro como Santa Fé. 


\section{Los agentes culturales}

Fueron muchos los agentes culturales de la ilustración. Criollos que fueran a Europa quizás no los hubo tanto como en Venezuela o en otras regiones. Voluntariamente fueron el fiscal Moreno y Escandón, Jorge Tadeo Lozano. Los más se desplazaron, o mejor, fueron desplazados por una razón que en la sociedad moderna ha sido buena aliada de la difusión cultural: la deportación o el exilio. Por esta vía viajaron Cabal, Zea, Nariño, Fermín de Vargas y muchos otros que quizás no dispusieran de fondos de un Bolívar, o acaso estuvieran más sumidos en el mediterráneo de sus montañas. En todo caso, a partir de entonces aprendieron a viajar.

En un comienzo fueron más importantes los agentes de difusión que venían de allende, y entre ellos figuran en primera instancia, como en toda América Hispana, los Virreyes y los funcionarios españoles, civiles o militares. Sin desconocer la radical influencia civilizadora de cada uno de los virreyes, mayormente caló en la sociedad granadina la personalidad de José Celestino Mutis (1732-1808). Su permanencia fue mucho más prolongada que la de los Virreyes (1760-1808), y mayor su compenetración con el medio, que permitía realizar una transferencia de conocimientos y sobre todo de moral. Nuestros valores científicos y aún las principales instituciones de investigación encuentran su raíz primera en esa personalidad y en su obra. Es legítimo hablar de José Celestino Mutis como líder carismático: sin ser científico de estatura universal (aunque fue sin duda grande), pues no produjo revolución científica, ni fue descubridor, ni acaso halló problemas nuevos de significación universal, Mutis introdujo una revolución espiritual en la Nueva Granada al ser agente residente de dispersión o de difusión del ethos de la ciencia, contenido en los paradigmas de Copérnico y de Newton en física, de Boerhave en medicina, de Linneo en Botánica. Con Linneo mantuvo correspondencia.

\section{Mutis o la vocación científica}

Mutis se propuso explícitamente como misión de su vida el cultivo de los valores de la ciencia. Fue en España, después de Feijoo, una de las figuras más caracterizadas en la encarnación de los ideales científicos. Mutis quería seguir los pasos del botánico Hernández que en el siglo XVII había explorado la Nueva España. Se proponía rehacer la gloria de España en América por medio de la ciencia, y por ello desechó ofrecimientos de la Corona para formarse en París o en Londres, que quizás le hubieran hecho mayor bien individual.

Llegó al Nuevo Reino porque estaba situado en el Nuevo Mundo, pero no por una elección deliberada, que quizás le hubiera marcado la ruta de Nueva España o del Perú. El escenario pudo no ser afortunado para la realización de su vocación, por la distancia respecto a los centros científicos, por la medianía de sus instituciones políticas y culturales.

En todo caso la presencia gratuita de Mutis en el Nuevo Reino fue definitiva para elevarlo de la opacidad en que hubiera permanecido acaso sin su presencia. Ante la historia es legítimo proceder imaginariamente y preguntarse en este caso lo siguiente: ¿qué hubiera ocurrido en el Nuevo Reino si Mutis no hubiese permanecido en él? ¿Qué le hubiera ocurrido a Mutis si hubiese ido a Nueva España? Al formular estas preguntas se pueden ponderar algunos factores de la acción humana: la influencia del azar, el papel que juegan los individuos en la historia, pero también el peso específico del medio social y cultural para determinar el margen posible de la libertad humana. 
Mutis permaneció en el Nuevo Reino a todo lo largo de 9 administraciones virreinales y por cerca de medio siglo. Se radicó tanto en el Nuevo Reino que murió en él poco antes de la independencia, hechos decisivos para el éxito de la difusión cultural. Aunque las instituciones culturales de México o del Perú fueron superiores, las Expediciones Botánicas tuvieron una duración limitada, aunque ciertamente dejaron instituciones más permanentes. Mutis había propuesto con mucha anticipación y mayor juventud (1764), y desde el terreno, la realización de Expediciones Botánicas y Mineras que no se llevaron a cabo, porque las ideas de Mutis se colocaban por encima de las urgencias de la Corona empeñada entonces en la defensa del regalismo, y por encima del medio que hubiera carecido entonces de colaboradores.

Mutis entre tanto se adaptó al medio del Nuevo Reino, conociéndolo a fondo como minero privado que fue, como sacerdote que se hizo, como médico y asesor de virreyes, como empresario de quinas, como pedagogo y en fin, como mecenas del talento que él había estimulado. Esta combinación de roles le permitió ejercer una influencia reconocida sobre la juventud (era llamado "oráculo del Nuevo Reino") y atreverse a dar combate a la orden que impugnaba aún la teoría de Copérnico y no la aceptaba siquiera como hipótesis.

Por otra parte, empero, las muchas actividades son indicio de una excesiva demanda sobre una personalidad que acusaba a momentos el exceso de responsabilidad, y testimonio de la precaria diferenciación cultural y científica del Nuevo Reino. Bajo esta luz han de juzgarse los evidentes fracasos de Mutis y de la Expedición Botánica en la minería, en el fallido estanco de la quina y sobre todo en la demora de la publicación de la Flora: obra póstuma como ninguna pues sólo comenzará a publicarse a poco menos de dos siglos de la venida de Mutis al Nuevo Reino, comprometiendo el esfuerzo de cerca de cuatro generaciones de botánicos.

\section{La elevación del medio}

La adaptación al opaco medio, no sin conflictos, le permitió de todas maneras integrar lo mejor de la tradición indígena y criolla con el espíritu de la ciencia moderna. Su ilustración está fuera de duda, y bien la prueba la biblioteca compuesta por cerca de 8.000 volúmenes, descomunal, dado el aislamiento del Nuevo Reino.

De la mayor importancia fue su actitud de integrar el saber teórico con el saber y el arte prácticos. Esta fusión fue decisiva como premisa en el siglo XV y XVI para el surgimiento de las Academias y en general de la ciencia. Tanto más decisivo era este fenómeno en el Nuevo Reino, porque las obras manuales, como en España, aunque quizás en menor grado, no pasaban por dar estima a las clases superiores. En Caldas se llevará a plenitud esta integración: Caldas, como se sabe, fabricaba sus propios instrumentos. Pero el caso se refleja igualmente en la pintura y en la incorporación de baquianos y prácticos a la obra de recolección de la Expedición Botánica. Un ejemplo quizás más característico fue el de Matis, un típico mestizo que resistía con toda la fuerza del hábito los paternales o autoritarios Ilamados de Mutis a que dejara el natural camino de las bestialidad. Matiz, el más longevo sobreviviente de la Expedición Botánica, obraría como figura simbólica en las siguientes generaciones para mantener viva la llama de la botánica (influyó sobre Céspedes, sobre Bayón y sobre Triana).

La organización de la empresa siguió los lineamientos trazados por Campomanes en la reglamentación de los gremios. No era propiamente una empresa capitalista, pues se organizaba sobre la base de unidad de residencia y lugar de trabajo, sobre una base de 
paternalismo y autoritarismo familiar, pero no por ello dejó de ser altamente racional para el control del trabajo y de las costumbres.

\section{La proyección del carisma}

En su labor docente y en la organización de la Expedición Botánica (1783-1817) Mutis inculcó en los discípulos, por medio de controles y de estímulos y recompensas, el ethos de la ciencia. Mutis introdujo en el Nuevo Reino instrumentos de medida. Fundó el observatorio (segundo en toda América). Avanzó en el estudio de la flora. Creó las bases para la fundación de los estudios médicos. Propuso la creación de un colegio de minería. Difundió las teorías de Newton, de Boerhave, de Linneo. Dio normas agronómicas para el mejor cultivo de la quina. Estimuló el talento americano. Impulsó el cambio de motivos en el arte, tanto en la pintura como en la literatura. Creó una conciencia de aplicación del talento americano para el estudio de problemas americanos. Y enseñó por vía de ejemplo o como modelo de rol una ética de independencia, de libertad y de disciplina personal, una moral de desconfianza y escepticismo respecto a creencias y supersticiones dominantes, una actitud de distancia frente a autoridades que carecieran de ilustración, elementos éticos éstos que sin duda obraron como fuerza especial en la generación de la Independencia.

El elemento integrador de la cosmovisión de Mutis fue el deísmo, o sea la concepción de que la naturaleza y la sociedad mantienen un orden: su estudio y el arreglo de la conducta de acuerdo a las leyes naturales son alabanza a Dios que lo creó. Este elemento del deísmo será pieza maestra en la racionalización de la religión en Colombia y acaso uno de los antecedentes más decisivos de la orientación ideológica del conservatismo en el siglo XIX que, como se sabe, fue partidario del estudio de la naturaleza en mayor medida que el liberalismo. Es sorprendente seguir, a partir de Mutis, la huella de sacerdotes interesados por el estudio de la botánica, desde Valenzuela a Pérez Arboleda, pasando por la figura de Céspedes. Pero el deísmo penetró igualmente en los civiles, como en Caldas, e incluso en una figura tan turbulenta intelectualmente como Florentino González. Habría de subrayarse, por esta vía, que a diferencia de México o de otros países latinoamericanos, no surgió entre nosotros un auténtico ateísmo, y que la asimilación del positivismo tuvo en nuestro medio características muy selectivas y especiales.

La obra de la Expedición Botánica se proyectaba primordialmente a la identificación científica de recursos naturales útiles, pero por este camino enlazaba directamente la ciencia natural con la social (en geografía, en antropología, en economía). En Fermín de Vargas y en Lino de Pombo se traducía el espíritu ilustrado en el examen de las relaciones entre población, trabajo, territorio y recursos. Es importante destacar que en esta materia los discípulos iban más allá que el maestro, pues disputaban su idea del estanco, que decidía sobre el control político de los recursos económicos. En Francisco José de Caldas fue clara la conexión entre astronomía, botánica y geografía, más avanzada que la de Mutis por una concordancia en gran medida intuitiva con la síntesis de Humboldt. Caldas expresó filosóficamente esta posición en un artículo donde se mezclaban en un difícil equilibrio el deísmo y el determinismo geográfico ("Influencia del clima sobre los seres organizados"). En el Semanario dirigido por Caldas publicó también José Manuel Restrepo una geografía sobre la provincia de Antioquia. Jorge Tadeo Lozano en su Fauna Cundinamarquesa, lamentablemente inédita, acercaba antropología y zoología al ubicar al hombre granadino en su medio natural. 


\section{Los límites de la ciencia}

Bajo la dirección de Mutis, sus discípulos habían logrado una emancipación mental que los ponía en condiciones de pensar que estaban en capacidad de controlar en propio beneficio los recursos del territorio. Una revolución de ideas se anticipó a una revolución política, fenómeno nada raro en la historia del mundo. Por supuesto, no sólo se debe a Mutis esta revolución: el contrabando intelectual, la asimilación de ideas de los deportados, y el clima general del mundo napoleónico ya permitían una aproximación individual a las ideas más avanzadas de la llustración, o mejor, a las ideas de Enciclopedia, ajenas a Mutis.

Empero, la conexión entre ciencia y política es altamente problemática. Son estas actividades que se complementan tensamente en instituciones totales, pero que son incompatibles si las llevan a cabo los mismos individuos. El demonio de la política es absorbente. De hecho, después de 1810 los discípulos se vieron agobiados por responsabilidades políticas y militares, y ya antes de 1817, cuando fueron llevados a España los restos de la Expedición Botánica, ésta había desaparecido como empresa. Por lo demás, la élite preparada por Mutis fue sacrificada casi en su totalidad por Morillo, que bien sabía el valor de una cabeza bien puesta en su sitio.

Por otra parte, la labor de Mutis y de sus discípulos se había realizado en buena medida contra el medio: no siempre la Corona valoró debidamente sus actividades y en la masa de 30.000 habitantes de Santafé, por hablar de todo el Nuevo Reino, no había ningún fervor por esa empresa esotérica. Voladores y corridas de toros fueron la mayor preocupación de sus habitantes el día de la muerte de Mutis, que coincidió con la jura de Fernando VII. No se los puede culpar: ¿Qué otro punto de referencia tenían? Caldas urgía por entonces al celo patriota para que apoyara las dos primeras escuelas públicas. En ese vacío de una masa no penetrada por la ilustración, no era extraño que los amigos de Mutis fueran llamados despectivamente bajo el nombre de la "compañía de los sabios", y el escaso público letrado no era muy permeable a publicaciones que no fueran de amenidades, es decir, a revistas "serias" que dieran dolores de cabeza. Caldas se quejaba en el Semanario del escaso número de suscriptores.

De esta suerte, no podríamos hablar bajo ningún concepto en este período de institucionalización de la ciencia en la sociedad del Nuevo Reino. Tanto menos cuanto que la universidad no se había acomodado tampoco a los valores de la ciencia.

\section{La tradición conventual}

A diferencia de Nueva España o del Perú, el Nuevo Reino, pobre en plata y de mediana economía, constituido apenas en 1739 como Virreinato, careció de universidad regia en el período colonial. En su lugar conté con universidades caseras o conventuales, como las llamó Sor Agueda Rodríguez, regentadas por órdenes religiosas. Dominicanos y jesuitas habían disputado agriamente en el siglo XVII el favor real para obtener el monopolio de grados en sus universidades Tomística y Javeriana (en realidad, colegios mayores). En 1704 se zanjó el conflicto al darse poderes a una y a otra: la rivalidad pudo haber introducido cierta emulación entre las dos instituciones, pero limitada apenas a finales del siglo XVII a un humanismo restringido. La ausencia de imprenta, la medianía de la cultura habían limitado la diferenciación del saber.

Apenas con el establecimiento del Virreinato se avanzó en la secularización del derecho, hasta entonces limitado casi enteramente a los estudios canónicos. A diferencia 
de México y de Perú, los estudios coloniales universitarios en medicina fueron precarios (hasta 1804 se crearían bases sólidas para una facultad de medicina).

En el siglo XVIII, los jesuitas contribuyeron al avance de la educación. Ellos introdujeron en 1739 por primera vez la imprenta; por otra parte, habían hecho aportes de peso al conocimiento de América en lenguas indígenas, en geografía e historia. Entre ellos se destacaron el relato del Padre Cristóbal Acuña sobre el Amazonas (Relación sobre el descubrimiento del Amazonas, 1640). El levantamiento de mapas del mismo río por el jesuita alemán Samuel Fritz (1564-1728), publicado en Quito (1707). La obra de José Gumilla: El Orinoco, ilustrado (1741). La de Cassani: Historia de la provincia de Santa Fe, materiales todos que sirvieron de fuente documental a La Condamine, a Mutis o a Humboldt. Introdujeron, aunque tenuemente, algunos aspectos de la ciencia natural de Descartes, si bien el conjunto de las ideas del discípulo de los jesuitas había sido rechazada en principio por la Compañía de Jesús. En la primera mitad del siglo XVIII extendió y consolidé la Compañía la educación en el Nuevo Reino, con los colegios menores abiertos en Popayán, Buga, Antioquia, Cartagena, Pamplona, Pasto y Tunja.

Con todo, fue la venida de Mutis el factor que contribuyó más notoriamente a la transformación relativa de los estudios universitarios. Mutis causó una primera conmoción con la enseñanza y defensa abierta del sistema heliocéntrico en tesis expuestas en la inauguración de su cátedra en el Real Colegio del Rosario de Santa Fe de Bogotá, en 1764. Esta actitud costó a Mutis la impugnación ante el Tribunal de la Inquisición, que no surtió efecto por el apoyo que las autoridades virreinales dieron al sabio.

En 1767 fueron expulsados los jesuitas de España y de sus colonias por Carlos III. La medida se orientó antes que a la secularización de la enseñanza, a la defensa del regalismo, impugnado por la orden a la que habían pertenecido Suárez y Victoria, y por quienes en América hispana habían conformado un estado dentro del Estado en las reducciones del Paraguay, ordenadas bajo la inspiración de la utopía de Moro.

\section{Las reformas de Moreno y Escandón}

Al fiscal Moreno y Escandón se debió el primer esfuerzo por transformar la universidad colonial del Nuevo Reino. Moreno y Escandón había conocido recientemente en España el intento de la élite ilustrada por modificar las vetustas instituciones universitarias. En Santa $\mathrm{Fe}$ es presumible que Moreno y Escandón recibiera el apoyo de Mutis para modificar la universidad ante el hecho cumplido de la expulsión de los jesuitas. Mutis no era adverso a la Compañía. Había sido educado por ellos. Su hermano era jesuita y un maestro suyo en Cadiz, también jesuita, era profesor en el colegio de la Compañía en Popayán.

Moreno y Escandón propuso en 1768, y luego en 1769, por primera vez y en forma consistente, la creación de una universidad Regia y secular donde "con acertadas reglas, a la vista del Reino y del Uniberso se instruía la juventud en sana doctrina y verdaderos fundamentos de las ciencias, alentándose con la esperanza de obtener las mismas cáthedras que emprende, porque su provisión por oposizión no sólo contribuie a que se confieran a los más dignos y beneméritos, sino que sirve de incentivo a la emulazión y al estudio"1.

\footnotetext{
${ }^{1}$ Hernández de Alba Guillermo. "Proyecto del Fiscal Moreno y Escandón para la erección de Universidad Pública en el Virreinato de la Nueva Granada, con sede en la ciudad de Santa Fé de Bogotá, año de 1768. En: Boletín del Instituto Caro y Cuervo, XVI, 1961, p. 471 a 493).
} 
Moreno y Escandón ponía de presente el desarreglo de la enseñanza, la falta de oportunidades para que los criollos laicos ejercieran su talento, el atraso de las ciencias, diagnóstico que ya había realizado Antonio de Ulloa en 1735, a su paso por Cartagena.

Sin embargo, y como sucedió en España, no tenía el estado ni la fuerza ni los funcionarios para remplazar rápidamente a los jesuitas en la educación. El vacío fue llenado por dominicos y agustinos, éstos más afines entonces a la ciencia moderna, pero menos numerosos. El proyecto fracasé porque, de una parte la orden Dominicana oponía resistencia por razón de su interés creado: al ser expulsados los jesuitas, la Tomística quedaba con el monopolio para otorgar grado. De otra parte, se opuso el Colegio de San Bartolomé, ahora regentado por seculares y por clero diocesano, aunque sus profesores, como sus estudiantes, se veían en la situación de una anómala dependencia frente al otro establecimiento.

\section{El "Methodo"}

De cualquier forma, Moreno y Escandón sacó el máximo partido público de la administración de los bienes confiscados a los jesuitas. En 1977 inauguré la biblioteca pública y en 1774 logró hacer aprobar un reglamento de estudios para la enseñanza, el "Método provisional e interino de los estudios que han de observar los colegios de Santa Fe, por ahora y hasta tanto que se erige Universidad Pública, o su Majestad dispone otra cosa, $1774 " 2$.

El método introducía ideas innovadoras en el Virreinato de Nueva Granada: reglamentaba las escuelas, Ilamando la atención (antes que Caldas volviera sobre el tema) sobre la escasez de maestros preparados. En filosofía combatía la escolástica y apuntaba a la enseñanza de la filosofía moderna a través de las matemáticas, de la física y en fin, de las ciencias útiles, sin que fuera en su llamado tan lejos como lo haría posteriormente Caballero y Góngora.

En su mira estaba hacer del clero una fuerza más útil para el progreso, una tendencia que también será expresa en Fermín de Vargas: "En la carrera más común de los eclesiásticos de este reino que es la de curatos. —decía el fiscal- serán infinitas las utilidades que resultarán de esta instrucción en beneficio propio y común en un país cuya geografía, historia natural, las observaciones meteorológicas, el ramo de la agricultura, y el conocimiento de sus preciosos minerales están clamando por la instrucción, que sólo pueden lograr los curas para dirigir a los demás hombres en sus parroquias. Este será el origen de donde saldrá el influjo universal para el fomento de la agricultura, de las artes y del comercio de todo el reino, cuya ignorancia lo tiene reducido al mayor abatimiento"3.

En teología, Moreno y Escandón introducía el contrato directo con la Biblia por encima de las interpretaciones escolásticas y doctrinarias, lectura que habría de apoyarse en conocimientos de historia, de geografía y de lenguas, como lo había indicado ya Erasmo en el Renacimiento. Insinuaba las bondades del cristianismo primitivo, es decir, de una religión interior depurada de ritos innecesarios. Combatía el espíritu de partido.

En jurisprudencia Moreno y Escandón introducía las doctrinas regalistas y ponía el acento en las ideas de la soberanía del Estado. Recomendaba textos como los de Van Espen y otros tratadistas galos que habían estado cerca del jansenismo. Indicaba la

\footnotetext{
${ }^{2}$ En: ICFES. compilación de normas sobre la educación superior. Vol. I. La Colonia, Bogotá, 1974, p. 97 a 118.

${ }^{3}$ Ibid. pág. 102 y 103.
} 
necesidad de asegurar de veras las enseñanzas de la medicina, previniendo contra la charlatanería y el empirismo que habían dominado la práctica médica. Acompañaba estas reformas de contenido, de nuevas reglas de enseñanza, como la de moderar los castigos y suprimir los dictados que no garantizaban otra cosa que autoritarismo en desmedro de buenas inteligencias.

\section{Las pausas}

El "Méthodo", sin embargo, fue impugnado aduciendo falta de fondos y de profesores. Estas razones debieron ciertamente jugar un papel: no había aún imprenta que tuviera la capacidad de publicar textos, ni biblioteca suficiente para contener los libros indicados, ni profesores preparados en la nueva mentalidad.

Pero las causas pueden ser más complejas: ¿una razón conservadora en la oposición a la modificación de los estudios jurídicos acaso tendría una significación revolucionaria? Es una tesis que ha sido sugerida, pero no explorada: la reforma estaba encaminada como hemos visto a sostener el punto de vista de la soberanía del Estado, tesis absolutamente contraria a la tradición de la doctrina tomista y jesuítica de la justa rebelión contra el tirano cuando altera los principios del bien común. ¿Obraron los abogados seculares de Santa Fe con inteligencia y astucia sobre lo que significaba retornar al antiguo estado de cosas? En todo caso, la historiografía ha indicado, sin calificarlo, el aspecto conservador de la restauración que se realizó con el "Plan de estudios de 1979"4.

Y resulta evidente, de todos modos, su espíritu conservador, cuando indica el documento que "se observe otra cosa, en los estudios de ambos colegios, procurando en lo posible ygualarlo al qe. antes del Plan sirva de Gobierno, para cautelar de este modo qe. con una absoluta novedad, se sienten malos efectos, qe. esta suele traer". Es decir, se insistía en el latín. Se recomendaba que se "enseñe del modo escolástico qe. hantes pero separando, y purgando de ha todas cuestiones, qe. por reflexas e impertinentes, se reputan pr. inútiles”. Se volvía a la enseñanza de Boudín, y significativamente a la doctrina de Santo Tomás.

\section{Renovados planes}

En 1777 el arzobispo virrey Caballero y Góngora retomé con mayor vigor la idea de crear una universidad pública y trazó un plan de estudios más avanzados para la época y el medio. "El estudio de ciencias inútiles, decía, no ha causado mal tan grave como el método que se observa en la educación de la juventud. Se ha adaptado ésta a las fatuas máximas de aquéllas, y en lugar de la educación civil que tanto influye sobre la felicidad del hombre y de las naciones de aquélla que prepara los jóvenes a llenar con suceso las diferentes profesiones de la Iglesia y del Estado, se practica la que sólo es propia a formar vasallos ociosos, inútiles a sí mismos y acaso gravosos a la humanidad. Sería pues necesario disipar aquellas ideas gravosas con que se crían los niños, y reengendrar por decirlo así una educación juiciosa sobre los sólidos fundamentos de la Religión y de la vida civil..."

El plan del Arzobispo Virrey iba más lejos que el propuesto por Moreno y Escandón: introducía cátedras de matemáticas, de química y de botánica (según los principios de

\footnotetext{
${ }^{4}$ Ibid., p. 119 y sig.

5 "Plan de Universidad y Estudios generales que se propone el Rey Nuestro Señor, para establecer, si es de su Soberano Real Agrado, en la ciudad de Santa Fe, capital de Nuevo Reino de Granada”, publicado en: Pérez Ayala, José Manuel. Antonio Caballero y Góngora. Bogotá, Imprenta Municipal, 1951, ediciones del Concejo, p. 267 a 283.
} 
Linneo). La enseñanza sería práctica, para lo cual se fijarían mapas de geografía, se adjuntaría un Jardín Botánico, un Museo de Historia Natural, máquinas, laboratorio químico farmacéutico, etc.

El plan no fue aprobado, y a partir de aquí será evidente una ambigüedad de las autoridades virreinales en materia de educación. Pero su mera enunciación debió tener efectos revolucionarios, pues en la joven generación de criollos, iniciados por Mutis en las ciencias útiles aplicadas al Nuevo Reino permaneció como ideal que de tiempo en tiempo se exigía a las autoridades virreinales. En todo caso, Camilo Torres en su Memorial de Agravios, José Félix Restrepo en su discurso en favor de la abolición de la esclavitud exagerarán al máximo la denuncia a la Corona por desproteger la educación y por evitar que los criollos accediesen a has dignidades supremas de la administración virreinal.

\section{Ciencia y educación}

Las actividades científicas se llevaron a cabo al margen de la universidad y sin colaboradores específicamente preparados para tareas especializadas. Las cátedras de Física en la Facultad Menor de Filosofía eran apenas el único contacto del universitario con el espíritu de ha nueva ciencia, pero corno señalaba Caldas al referirse a su maestro José Félix de Restrepo, era apenas tosca la idea de la física, carentes como estaban las universidades de libros e instrumentos. Caldas subraya que debió aprenderlo todo de nuevo por propia cuenta, una queja que por lo demás será característica de la edad moderna dominada por el progreso científico-técnico.

Mutis realmente no ejerció por mucho tiempo tareas docentes en la Universidad. Sin embargo, fue maestro de maestros, al formar a Félix de Res-trepo que orientaría en Popayán hacia la ciencia a Camilo Torres, a Caldas, a Zea y a Lino de Pombo, entre otros. Zea y Restrepo, sobrino y tío, eran de Medellín o más propiamente de Envigado. Restrepo y Caldas formarían luego, hacia 1814, parte del gobierno liberado de Antioquia, fundando una Escuela de Ingeniería con propósitos similares. A su vez Lino de Pombo se estableció en Cartagena, como asiento para sus importantes negocios. Allí propondría hacia 1808 una reforma de los estudios en un espíritu afin al que había inspirado la idea de Caballero y Góngora. De esta suerte, las ideas de una educación en los valores de la ciencia y de la técnica se difundieron a todo el Nuevo Reino a través del control de Santa Fe, su capital, y siempre bajo el hilo conducto de Mutis, quien mantenía correspondencia con Lino de Pombo, Caldas, Zea en España y otros.

Mutis suplía la deficiencia en la preparación universitaria de sus colaboradores (Zea, Valenzuela), mediante clases privadas. Dio lecciones priva. das también a Vergara, su suplente en la cátedra de matemáticas. Finalmente, la influencia directa de Mutis sobre la Universidad se tradujo en la redacción del Plan de Estudios para la Facultad de Medicina, que dirigiría Isla desde 1804.

Caldas, por su parte, resumió los ideales pedagógicos y su pasión por los valores científicos y técnicos en diversos escritos, y principalmente en las páginas del Semanario (1808). En eh "discurso sobre la Educación" urgía la necesidad de una educación pública, gratuita y uniforme, siguiendo los ideales borbónicos que habían planteado Campomanes y Jovellanos en España. Preocupación por la enseñanza superior práctica mostró en "Plan Razonado de un cuerpo militar de Ingenieros mineralógicos en el Nuevo Reino de 
Granada", en el "Reglamento que debe gobernar el Real Cuerpo de ingenieros mineralógicos en el Nuevo Reino de Granada", y en general en todos sus escritos ${ }^{6}$.

\section{A modo de balance}

En síntesis, si no cabe hablar bajo ningún concepto de institucionalización de la investigación científica, ni mucho menos de una comunidad científica, bien por la distancia de élite y masa, bien por la separación de actividades científicas y técnicas de la Universidad, bien por ha carencia de continuidad debida al sacrificio de la élite, bien por la tenue separación de ciencia y política, o por la escasa diferenciación entre ciencia y religión, o bien por la indiferenciación de roles e instituciones que reflejaban de alguna manera la relativa pobreza del Reino, sí puede señalarse que en el período constituido por la venida de Mutis (1760) y la liquidación de la Expedición Botánica (1817) se definió con un perfil bien saliente el "ethos" de la ciencia y de la técnica adaptado a las circunstancias culturales y exteriores de una incipiente nacionalidad.

¿Cómo se extendió? En ha historiografía tradicional se ha tendido a exagerar la discontinuidad. En un examen más detenido de la materia se podrá señalar que a pesar de los evidentes saltos y quiebres, estos valores arraigaron de tal modo que se hicieron irreversibles y a partir de allí constituyeron un elemento ineludible de la orientación espiritual de la nación.

\footnotetext{
${ }^{6}$ Universidad Nacional de Colombia. Obras completas de Francisco José de caldas. Bogotá, Imprenta Nacional, 1966. No son tan completas como reza el título.
} 